\title{
ÉTICA Y EDUCACIÓN EN TORNO AL PENSAMIENTO DE CARLOS DE LA ISLA* Rodolfo Vázquez**
}

\begin{abstract}
Agradezco al Dr. Carlos de la Isla su honrosa invitación para comentar ésta, su más reciente publicación, De esclavitudes y libertades. Mi agradecimiento es doble porque me permite compartir la mesa con queridos colegas y amigos, entre ellos uno ausente que sé que en estos momentos acompaña al Doctor y a este evento con todo su ánimo y cariño, Alberto Sauret.

De la gran variedad de interrogantes que se desprenden de este rico y provocativo libro quiero centrar mi atención en una de ellas planteada en los propios términos del autor: ¿Cuál es la teoría ética más defendible? (p. 125) Para ser más precisos: ¿Cuál es la teoría ética defendida por De la Isla y que sirve de fundamento para su concepción de la educación?

Para guardar cierto orden en la respuesta es conveniente recordar que en las discusiones contemporáneas sobre el papel de la ética en la reflexión filosófica se distinguen tres niveles de análisis. El primero tiene que ver con los enunciados éticos, su valor de verdad y el

* Los siguientes textos fueron leídos por sus autores (salvo el segundo, leído por Patricio Sepúlveda en ausencia del autor) con motivo de la presentación del libro del doctor Carlos de la Isla, De esclavitudes y libertades, 2006, México, ITAM-Miguel Ángel Porrúa, 300 p., el mes de abril de 2006 en la Biblioteca Gómez Morín del campus Río Hondo del ITAM.

** Departamento Académico de Derecho, ITAM.
\end{abstract}


significado de los conceptos morales (metaética). El segundo se refiere a los argumentos en favor o en contra de las acciones humanas y a los principios que las regulan (ética normativa). El tercero describe los comportamientos morales y las reglas que los rigen (ética descriptiva). El libro no es un tratado de sociología moral así que me detendré en los dos primeros niveles de análisis, el metaético y el normativo, que constituyen el núcleo de la reflexión del autor, y reservaré para el final algunos comentarios sobre la educación a partir de su justificación ética.

\section{Metaética: objetivismo moderado}

En el ensayo "Algunas doctrinas éticas", De la Isla comienza descartando, con razón, dos posiciones metaéticas extremas: el subjetivismo y el absolutismo. El primero, al menos en su versión relativista, cae en la falsedad, 'se devora a sí mismo'; el segundo, pretende el conocimiento total de la verdad y puede llegar a extenderse a 'una actitud ética y política peligrosa y criminal', dogmática e intolerante.

Entre el relativismo y el absolutismo cabe una tercera posibilidad: el objetivismo. Es verdad que existe una tendencia común a creer que cualquier alejamiento del absolutismo moral, por mínimo que sea, conduce irremediablemente al relativismo o a la arbitrariedad, pero pienso con De la Isla que esta creencia es falsa. Ya Isaiah Berlin ofreció buenos argumentos para la defensa de un objetivismo pluralista de los valores ante el reproche de Leo Strauss de querer ubicarse en un punto intermedio entre el relativismo y el absolutismo. Pero quizás no haya que llegar a la defensa del pluralismo valorativo, ni a la inconmesurabilidad de los mismos, como propone Berlin, para ser objetivista. Se puede partir, como lo hace De la Isla, de una versión más moderada, basada en el reconocimiento y valoración de las necesidades básicas como buenas razones para determinar aquellos bienes que merecen ser tutelados por un sistema normativo, sea moral o jurídico. Es la 
línea de argumentación abierta, entre otros autores, por Mario Bunge, Ernesto Garzón Valdés y Ruth Zimmerling.

Para Zimmerling, por ejemplo, las 'necesidades básicas' son un criterio objetivo y universal para fijar el límite inferior de la moral. Son objetivas en la medida que se habla de datos empíricos referidos a personas reales. Zimmerling se apoya en una cita de Wiggins: "A diferencia de 'desear' o 'querer' [... 'necesitar' obviamente no es un verbo intencional. Lo que necesito no depende del pensamiento o del funcionamiento de un cerebro [...] sino de cómo es el mundo." Por lo que hace a su universalidad, la misma autora distingue entre 'necesidades instrumentales y adventicias' y 'necesidades absolutas o básicas'. Las primeras descansan en la satisfacción de un fin contingente; las segundas en la de un fin que ya no necesita justificación, como por ejemplo, el fin de sobrevivir y el de preservar y restablecer la salud.

Es cierto que el reconocimiento de las necesidades básicas representa un 'límite inferior' de la moral. Autores como Amartya Sen y Martha Nussbaum han propuesto una ampliación de la teoría de las necesidades básicas con una teoría de las capacidades, sobre todo en Nussbaum, con una clara referencia a Aristóteles. Sea por la vía de las necesidades básicas o de éstas con la teoría de las capacidades, lo cierto es que ambas parten de un análisis de la condición humana, física y mental, a partir de criterios empírico-racionales.

La alusión a Aristóteles, por parte de Nussbaum, no es gratuita y tampoco es gratuito que De la Isla concluya su análisis de algunas doctrinas éticas con la defensa del pensamiento aristotélico. El objetivismo aristotélico le parece la metaética más defendible:

La ética aristotélica logra, sin duda, el equilibrio de los clásicos en la consideración y relación del hombre y de la sociedad: un hombre con sensibilidad, con razón insaciable de verdad, con una voluntad insaciable de bien, con una percepción estética insaciable de belleza, con una gran potencia de amar y de gozar el bien procurado a los demás. (p. 134). 


\section{Ética normativa: personalismo igualitario}

La adopción de algunas de las tres concepciones de la metaética ya señaladas, absolutista, subjetivista y objetivista, sirve de fundamento epistemológico a distintos tipos de éticas normativas y no es difícil pensar qué tipo de educación se desprenderá de cada una de ellas.

Una metaética absolutista constituirá el fundamento epistemológico de una ética perfeccionista y conservadora que justifica una educación monista y autoritaria. Una metaética subjetivista, en su vertiente individualista, constituirá el fundamento epistemológico de una ética libertaria donde las preferencias individuales, bajo criterios de eficiencia, son determinantes para la valoración moral de las acciones, entre ellas la educación; la misma metaética subjetivista, pero ahora en su vertiente relativista, constituirá el fundamento epistemológico de una ética comunitaria que justifica un modelo de educación integrista, orgánica o corporativa.

Desde una metaética objetivista, a partir de una teoría de las necesidades y capacidades del ser humano, como ya hemos visto, De la Isla fundamenta su ética normativa en el enunciado de tres principios y una concepción antropológica que se desprende de los mismos. Los principios normativos son el de dignidad, el de autenticidad y el de igualdad. Entre ellos existe un orden lexicográfico que perfila una ética normativa que denominaré 'personalista igualitaria'. Veamos.

De la Isla no es un liberal libertario que antepone al principio de dignidad e igualdad el valor del individuo y sus libertades ilimitadas. Manifiesta a lo largo del libro muchos reparos y un claro distanciamiento de autores como John Stuart Mill y su concepción del individuo soberano. Sólo a manera de ejemplo, cito el siguiente pasaje:

Si se piensa que el hombre es soberano sobre sí mismo, su cuerpo y su espíritu (J. S. Mill) entonces se convierte en 'medida de todas las cosas' (Protágoras) y de aquí se sigue el libertinaje del liberalismo extremo con la ética utilitarista, la arbitraria economía de mercado y la política del dejar pasar. Resultado: el mundo en que vivimos, las leyes 
que nos rigen, el capitalismo de las desigualdades, de las esclavitudes, de la violencia y el odio. (p. 291)

Podríamos discutir su interpretación de Mill y el nexo entre liberalismo extremo y utilitarismo, pero lo cierto es que el individuo y sus libertades no ocupan el lugar central en la ética normativa de De la Isla. Tal privilegio le corresponde al principio de dignidad.

Como se sabe, hay una larga tradición en el pensamiento occidental para acceder al principio de dignidad. Tradición que se extiende hasta los filósofos modernos y contemporáneos. De la Isla, por ejemplo, no encuentra inconveniente en aceptar el imperativo kantiano, que ha servido también de punto de partida para el pensamiento de un autor como John Rawls con quien, por cierto, gusta de acompañarse a lo largo del libro citando su principio de diferencia. Pero si nos preguntáramos en qué se fundamenta la dignidad de una persona, qué hace de su humanidad un fin en sí misma y no un medio o una mercancía, la respuesta de De la Isla se encamina por una vía distinta a la de la modernidad liberal.

Un liberal, el propio Kant, intenta justificar la dignidad de una persona en la capacidad racional de proponerse fines, es decir, en la autonomía personal. Una persona es digna porque es autónoma. Hay una precedencia de la autonomía sobre la dignidad y esto constituye el núcleo central del liberalismo. Para De la Isla, sin embargo, la dignidad de una persona precede a su autonomía, por lo tanto, su fundamento hay que buscarlo no en el ámbito de las capacidades humanas sino en algo que justifique el valor absoluto de la dignidad y con ello su carácter de fin y no de medio. Un absoluto sólo puede fundamentarse en otro Absoluto, pero este último con mayúscula:

Por otra parte, si se habla de desarrollo humano es obligado partir de un concepto auténtico de lo que el hombre es. Y esta doctrina [hace referencia a la doctrina social de la Iglesia] difiere de las otras por el elevado concepto antropológico, cuya dignidad le viene de su parentesco con Dios. [...] Si [...] el hombre es considerado como hijo de Dios, primera consecuencia: todos los hombres deben ser tratados con inmenso respeto 
por su enorme dignidad; todos los hombres tienen el derecho a todos los medios para vivir y desarrollarse plenamente. (p. 291-2).

Del párrafo citado desprendo tres aseveraciones que merecen comentarse:

1. La dignidad de una persona se justifica por su participación en el Absoluto: una persona es digna porque es imagen y semejanza de Dios. El problema de la moral se resuelve, finalmente, en un problema metafísico.

2. El respeto a la dignidad de una persona es el punto de partida para el desarrollo de un ser humano auténtico.

3. La dignidad de una persona justifica la igualdad entre los seres humanos en tanto todos deben ser tratados con igual consideración y respeto.

Con respecto al primer punto, la concepción ética de De la Isla podría adjetivarse como personalista y no como individualista. Esta última, más acorde con una concepción liberal, subordinaría, como ya dije, el principio de dignidad al de autonomía; no apelaría tampoco

146 a un fundamento metafísico. Ahora bien, ¿qué tan necesaria es, en última instancia, una metafísica cristiana para justificar el principio de dignidad personal? Por el texto citado no cabría duda alguna de su necesidad. Sin embargo, tengo la impresión, por otros pasajes del libro, que De la Isla no considera necesaria la apelación a Dios para justificar la dignidad de la persona. Muchos pensadores de confesión cristiana, entre ellos John Finnis o Max Charlesworth, no han visto necesario establecer tal nexo, aunque su argumentación no se encamina por la vía de la dignidad sino por la de la autonomía personal. Creo -aunque me gustaría dejar abierta la pregunta- que es ésta también la vía de De la Isla, si bien la autonomía no se entiende ya como la capacidad del individuo soberano, a la Mill, sino como autenticidad.

Por ello, con respecto al segundo, el reconocimiento de la propia dignidad es el punto de partida para la construcción de un ser humano auténtico. Pero, ¿qué es la autenticidad?: 
Autenticidad es una palabra que expresa, primariamente, la afirmación del yo mismo; el término griego autós significa mismo y sustantivado equivale a mismidad o autenticidad. El hombre es él mismo, auténtico, cuando su propio ser, su historia es decidida, es construida por él mismo. [...] Si las ideas son propias, si son el fruto de la meditación angustiosa por la verdad y el bien, si son fuerza poderosas que se convierten en una vida apasionada e ilusionada con marcha firme hacia metas claras, entonces estamos hablando de hombre auténtico. (p. 254-5).

La vida se entiende como autorrealización, como una genuina 'agonía'. La antípoda clara del sometimiento y de las esclavitudes. La autonomía comprendida, entonces, como 'austera plenitud'.

Por lo tanto, con respecto al tercero, son la dignidad y esa posibilidad de construcción del individuo auténtico los fundamentos para el tratamiento del otro con igual consideración y respeto. Y este principio de igualdad comienza a concretarse cuando el Estado y los mismos individuos asumen los deberes correspondientes para satisfacer las necesidades básicas e incrementar las capacidades de cada individuo. Todo ello en el marco del reconocimiento, la implementación y la promoción de los derechos humanos:

En la época actual la defensa de los derechos humanos tiene también supuestos implícitos de objetividad y de universalidad, como son la dignidad que funda la igualdad y la libertad, derechos que son raíces esenciales de la persona. La teoría del igualitarismo tiene a su vez como fundamento la igualdad que proviene de la dignidad personal, por eso el sabio criterio de Rawls: 'lo justo es distribuir a todos por igual y las diferencias sólo se justifican cuando son a favor de los más débiles'. (p. 18).

Al personalismo como primera adjetivación de su ética, agrego ahora el igualitarismo. La dignidad como fundamento no de una vida egocéntrica sino responsablemente igualitaria.

La conjunción de estos tres principios - dignidad, autenticidad e igualdad- constituyen una mezcla poderosa para hacer de De la Isla 
uno de los críticos más mordaces del individualismo mercantilista, de los 'poderosos capitalistas', de los 'explotadores del hambre de los pobres y miserables'. Sus mejores páginas están dedicadas a desenmascarar la falsedad y la perversidad de esta concepción ético-política y económica.

Pero de igual manera, creo que esa misma conjunción de principios acerca a De la Isla, al menos como compañero de ruta, a ciertas formas de socialismo moderado, especialmente por su convicción de que de nada vale la lucha por los derechos civiles y políticos cuando las necesidades básicas de la gran mayoría de la población no están ni remotamente satisfechas; y de que si una democracia no es sustantiva y no garantiza la homogeneidad de la población en el reconocimiento de sus derechos sociales y culturales, es un simulacro de democracia. De la Isla se incomoda cuando escucha la crítica de los capitalistas al socialismo, no porque desconozca los posibles abusos de tal régimen sino porque no son precisamente los capitalistas o los defensores de un liberalismo a ultranza los que tienen la autoridad moral para criticar un sistema que al menos se dignifica procurando la satisfacción de las necesidades más urgentes de los seres humanos.

\section{Hacia una educación con responsabilidad social}

Finalmente, ¿qué teoría educativa se desprende de tales premisas metaéticas y normativas? ¿Qué valores deben animar la educación, especialmente la educación universitaria? En una síntesis apretada respondería con los siguientes enunciados:

1. Una educación en y para el diálogo. Acorde con su objetivismo y contra el dogmatismo y el relativismo, De la Isla privilegia la educación dialógica a partir de la evidencia empírica y la relevancia del discurso racional:

La comunicación, que para Jaspers es la esencia de la educación superior, se establece por el diálogo, traspasa el libro, porque esta comu- 
nicación no es ni una biblioteca muerta, ni un museo, sino una relación viva con grandezas e imperfecciones y dolencias. En esa relación el maestro es uno de los sujetos del diálogo y no el recitador teatral de la lección sin réplica. Maestro y estudiante afirman en su diálogo su propia existencia. (p. 47)

2. Una educación en y para la persona. Ello supone el reconocimiento de la dignidad del educando y el desarrollo de su autenticidad.

3. Una educación en y para la acción participativa y democrática. Educar para el reconocimiento de la pluralidad y la participación efectiva en la toma de decisiones institucionales. Ambas como antídotos necesarios contra la irracionalidad:

La universidad no educa para la paz cuando actúa en forma autoritaria, vertical e impositiva [...] La universidad es el recinto de la razón, y cuando la irracionalidad domina a la razón, ¿dónde podrá ponerse la esperanza de la educación para la paz, verdadero antídoto para la violencia? (p. 96).

Finalmente, y en la teoría educativa de De la Isla, ocupando un lugar central:

4. Una educación en y para el desarrollo de la responsabilidad social. A este respecto Gilberto Guevara Niebla ha señalado con toda razón que la universidad mexicana ha otorgado prioridad al sector moderno y ha puesto poca atención al mundo de la pobreza. Es hora ya de que:

las instituciones de educación superior vuelvan la vista hacia esa parte de la sociedad que es terreno fértil y rico para la investigación básica y aplicada, las prácticas docentes, el servicio social y actividades de extensión de todo tipo [...] las universidades pueden ayudar a las comunidades al ofrecer servicios (como salud, abogacía, contaduría, administración); llevar cultura a los pueblos (teatro, exposiciones, conciertos, cine); ofrecer becas de estudio y bibliotecas ambulantes; capacitar para el 
trabajo, alfabetizar, producir materiales de apoyo como libros técnicos, grabaciones y videos científicos y culturales. ${ }^{1}$

Por supuesto, esta tarea no es exclusiva de las universidades públicas, también lo es de las privadas. Sería un error partir de la idea de que la universidad -especialmente la privada-cumple su misión manteniéndose neutral ante los problemas que afligen a la sociedad y, especialmente, a los menos favorecidos. En este sentido, tiene razón De la Isla cuando subraya enfáticamente:

Hay quienes afirman que la Universidad cumple su obligación de justicia con la sociedad cuando forma profesionistas muy capaces en el campo de la ciencia y de la técnica. Pienso que este criterio es, por lo menos muy discutible, porque si bien es cierto que los buenos profesionistas mejoran el ejercicio de su profesión y ya así benefician a la sociedad, la falla radica en el modo distributivo del beneficio. Los estudiantes que ingresan a la educación superior ya son privilegiados; no importa si se trata de universidades públicas o privadas. Existe una inversión social muy importante y aun sacrificada en las universidades, especialmente en los países pobres y extremadamente pobres. Si esa inversión económica que sacrifica vastas áreas menesterosas de la sociedad tiene como resultado final la afirmación y acrecentamiento de los privilegios, entonces la universidad se constituye en reforzadora de diferencias sociales. ${ }^{2}$

La responsabilidad social debe convertirse, entonces, en un objetivo fundamental de cualquier ideario educativo pero, sobre todo, debe actualizarse como valor concreto dentro del proceso de enseñanzaaprendizaje. Una educación así entendida debe desplegar todos los medios para que el educando descubra el significado de su dimensión social, que perciba, como sugiere De la Isla, que "ni puede existir, ni por tanto crecer como persona si no es en y con la sociedad y así descubra las obligaciones que tiene en justicia de esforzarse y compro-

${ }^{1}$ Gilberto Guevara Niebla, La Jornada, 15 de abril de 1995, p. 15

${ }^{2}$ Carlos de la Isla, "La Universidad: conciencia crítica", en De la perplejidad a la utopía, 1998, México, ITAM-Coyoacán, p. 111. 
meterse con el mejoramiento de su propia sociedad". Si el sentido de responsabilidad social y el deber de promoverla son necesarios en cualquier sistema educativo, tanto en países desarrollados como subdesarrollados, en estos últimos se convierte en imperativo.

Por último, todo lo dicho hasta aquí puede ser un primer esbozo, muy general, del ideario ético y educativo de nuestro autor pero, por supuesto, este ideario carecería de alguna relevancia moral práctica si el autor no lo incorporara a su forma de vida. Quien como yo ha tenido la posibilidad de conocer y ser testigo de la actividad del Dr. Carlos de la Isla no me desmentirá si afirmo que nadie mejor que él ha encarnado el carácter propio de un universitario cabal: constituirse en conciencia crítica de la sociedad. Una conciencia incómoda, como no podría ser de otra manera, pero finalmente conciencia lúcida, con un profundo sentido de responsabilidad social. 
La reproducción total o parcial de este artículo se podrá hacer si el ITAM otorga la autorización previamente por escrito. 